\title{
EQUIDAD, DESARROLLO Y PAZ
}

\author{
Jorge Iván González*
}

\section{INTRODUCCIÓN}

De alguna manera intuimos que el modelo de desarrollo económico incide en la violencia. Sin embargo, es muy difícil mostrar cómo interactúa lo económico y lo social. Las causalidades terminan siendo circulares. Los fenómenos económicos y sociales se retroalimentan. La frontera que los separa es muy difusa.

La reflexión económica en Colombia se ha empobrecido frente a la consolidación de un pensamiento único. Las facultades de economía no han construido escuelas alternativas. La agenda del debate económico es definida por la corriente principal, que está muy influida por los dogmas de la ideología neoliberal. Esta falta de diálogo ha matado la creatividad. No encontramos salidas alternativas porque nuestras diferencias no han sido pensadas de manera diferente.

A comienzos de los noventa el país realizó una liberación cambiaria y una apertura comercial que modificaron radicalmente la estructura de la economía. La política monetaria pasó a desempeñar un papel central, hasta el punto de que la producción y el empleo se han sacrificado en aras de la ortodoxia monetaria.

La prelación de lo monetario en un contexto de globalización ha originado un desequilibrio entre las políticas monetaria y fiscal. Lo fiscal reacciona tardíamente a las decisiones tomadas en el frente monetario. Este sometimiento de lo fiscal a lo monetario ha reducido el margen de discrecionalidad del presupuesto que, en palabras de la Comisión de Racionalización (1997) ', se ha convertido en un instrumento "inocuo".

El costo social de la política económica ha sido elevado. Para tratar de suavizar este impacto, los programas sociales han puesto el énfasis en la lucha contra la pobreza. Este enfoque debe modificarse, de tal manera que en futuro la atención se centre en la equidad. La disminución de la concentración del ingreso y de la riqueza estimula el desarrollo, contribuye a reducir la pobreza y a crear un ambiente propicio para el diálogo y la paz ${ }^{2}$.

\section{LA HOMOGENEIDAD DEL PENSAMIENTO ECONÓMICO EN COLOMBIA}

Las ciencias sociales, entre ellas la economía, han tratado de aportar su grano de arena a la explicación de la natu- raleza del conflicto que está viviendo el país. La contribución del análisis económico ha sido pobre. Esta debilidad de la reflexión económica se debe a lo que llamaré: la uniformidad alrededor de la corriente principal.

La "corriente principal" tiene dos expresiones. Una polí tica, y profundamente ideologizada, que tiene su manifestación más clara en el "neoliberalismo". Otra de corte académico, que se ha construido alrededor del programa de investigación neowalrasiano ${ }^{3}$.

El discurso neoliberal ha tratado de mostrar que sus bases científicas provienen de Smith (1776) y Walras (1887). Pero entre la visión de estos autores y la proclama políticoideológica del pensamiento neoliberal hay una brecha enorme. Empezando porque el equilibrio del mercado de Walras no explica el funcionamiento de economías descentralizadas. La propuesta walrasiana supone la existencia de algún mecanismo centralizador. La figura del subastador cumple esta función integradora. La teoría económica ha tratado de introducir nuevos elementos con el fin de construir modelos menos restrictivos que el de Walras. La fundamentación que pretende hacer el pensamiento neoliberal en el modelo de Walras es poco rigurosa porque desconoce las limitaciones de los supuestos inherentes al equilibrio walrasiano.

Tampoco es legítimo fundar el discurso neoliberal en Smith, quien reconoce de manera explícita que el mercado es imperfecto ${ }^{4}$ y que hay esferas de la vida social, como la educación, en las que la lógica del mercado no opera ${ }^{5}$. La

* Profesor. Facultad de Economía. Universidad Nacional.

1. La Comisión de Racionalización del Gasto y de las Finanzas Públicas fue creada por la administración Samper (1994-1998) con el fin de proponer alternativas que permitieran desacelerar la dinámica del gasto público y mejorar su eficiencia.

2. El Departamento Nacional de Planeación (DNP, 1998: 41) muestra que hay una relación positiva entre violencia y desigualdad. "Si bien la pobreza aparece inversamente relacionada con el grado de violencia, la desigualdad aparece positivamente asociada con ella".

3. Se llama neowalrasiano por WALRAS (1887), quien simuló de una manera muy sencilla las condiciones que debería cumplir el mercado, para que al final del día -en el momento del cierre- todos los bienes ofrecidos se hayan vendido, sin que ninguno de los compradores quede descontento.

4. "los bienes no siempre obtienen dinero con la misma facilidad con la que el dinero obtiene bienes" (SMITH, 1776: 545). En tales circunstancias hay exceso de oferta.

5. A propósito de los gasto del Estado en educación, dice Smith: “... aunque ventajosos en sumo grado a toda la sociedad son, no obstante, de tal naturaleza, que la utilidad nunca podría recompensar su coste a un individuo o a un corto número de ellos y, por lo mismo, no debe esperarse que éstos se aventuren a fundarlas ni a mantenerlas" (SMITH, 1776: 639). 
filosofía moral de Smith no es una apología del mercado (Sen, 1987: 22 y ss.).

Gracias a la forma habilidosa como el discurso neoliberal se ha apropiado de las ideas de Smith y de los otros autores neowalrasianos, los argumentos en favor del libre mercado se presentan bajo un ropaje técnico, que oculta su raíz política e ideológica.

El discurso liberal es una continuación del monetarismo que tuvo su auge en América Latina en el decenio 1975. 1985. En aquel momento, la escuela de Chicago sirvió de manto técnico. Friedman, el autor más representativo del monetarismo, siempre ha aceptado que el mercado es imperfecto ${ }^{6}$. No está de acuerdo con que el monetarismo sea identificado con un pensamiento políticamente conservador: De lo uno no se deriva lo otro (Friedman, 1993: 178).

Arrow, quien recibió el premio Nobel en el 72, expresa su preocupación por la forma como los gobiernos neoliberales han ideologizado el mercado.

"Los mercados no son la solución a ningún problema. Los mercados no se interesan por el bienestar de los individuos porque la dinámica del sistema deja de lado las preguntas por la distribución. En los Estados Unidos y en Inglaterra ha ido creciendo una ideología del mercado. Fuera de otras patologías, estamos presenciando una caída en el bienestar de la población trabajadora" (Arrow, 1995, subrayado mío).

La "ideología del mercado", de la que habla Arrow, expresa la displicencia del discurso neoliberal frente a la forma crítica como algunos autores neoclásicos han asumido el mercado. "No sólo desde cl punto de vista de la eficiencia, sino también desde la perspectiva de la distribución, el capitalismo es un sistema muy imperfecto" (Arrow, 1995).

Es indudable que hay autores que en algunos aspectos están más cerca del pensamiento neoliberal que otros. Lucas (1987) y Sargent (1987), por ejemplo, que han sido los inspiradores de la nueva macroeconomía clásica, han defendido una idea que ha sido aceptada a pie juntillas por los neoliberales. Para la nueva macroeconomía clásica las medidas que se toman en el frente monetario no tienen ningún costo en el mundo real. Es decir, la llamada "tasa de sacrificio" es cero. Como mostraré adelante, este principio ha tenido una influencia muy grande en Colombia. Pero aún en el caso de la nueva macroeconomía clásica, hay una brecha entre la discusión académica y la forma como se hace la política económica. Desde hace 20 años, Lucas (1976) está diciendo que los modelos econométricos no se pueden aplicar para hacer proyecciones. Los parámetros de la regresión no son estables porque las condiciones políticas y estructurales de las economías van cambiando. A pesar de que la crítica de Lucas es contundente, la tecnocracia sigue suponiendo estabilidad paramétrica y continúa haciendo modelos predictivos que hacen caso omiso de las transformaciones intertemporales de las economías.

La tecnocracia colombiana ha jugado un papel determinante en la simplificación de la teoría. Ha facilitado la ideologización del lenguaje académico. Le ha proporcionado el ropaje técnico al discurso neoliberal. Nuestra tecno- cracia ha sido más papista que el papa. Detrás de la formalización esotérica ha ocultado una posición política ${ }^{7}$. No ha dejado aflorar el debate político porque habla un lenguaje que deja por fuera al contradictor. La ingeniería económica, que sirve de escudo a las decisiones políticas, es un idioma que sólo pueden hablar los iniciados ${ }^{8}$.

Durante los noventa, en las facultades de economía más prestigiosas del país se ha ido produciendo una convergencia hacia lo que podríamos llamar el "pensamiento único". Las bibliografías que se enseñan en los cursos básicos, especialmente en macro y microeconomía, copian los libros de texto propuestos por la corriente principal. No hay procesos conducentes a la formación de escuelas de pensamiento. La óptica analítica se ha unificado considerablemente y ello ha acallado el diálogo y la discusión (González, 1999).

Nuestros economistas entran en un circuito tecnocrático en el que ya no queda tiempo para examinar cuidadosamente cuáles son los principios teóricos que guían la política económica. Poco a poco se van asimilando las frases de moda. Y, como anota Krugman (1995), se van aceptando dogmas que no tienen fundamento ni en la teoría, ni en la realidad. El discurso neoliberal dice, por ejemplo, que la protección a la industria nacional es, per se, perjudicial. Krugman no está de acuerdo. Los costos de la protección difícilmente superan el 1\% del PIB y, en los casos extremos no pasan del 5\% (Krugman, 1995: 31). Quizás los costos de la liberalización hayan sido mayores que los de la protección.

En Colombia el debate económico es muy restringido porque no pone en tela de juicio los dogmas neoliberales. Normalmente la discusión comienza con el reconocimiento acrítico de los siguientes principios:

- La tasa de sacrificio de la política monetaria es cero.

- La lucha contra la inflación es el primer objetivo de la política económica.

- La independencia de la banca central favorece la estabilidad macroeconómica.

6. "Todos los economistas, sean monetarios, keynesianos, o de cualquier otra corriente, reconocen que existe algo como una falla de mercado. Creo que el punto de divergencia entre los economistas no es si ellos aceptan las fallas de mercado, sino qué tanta importancia le atribuyen a las fallas del gobierno, especialmente cuando éste busca remediar las fallas de mercado" (FRIEDMAN, 1993: 174).

7. "Muy poco del entrenamiento profesional que reciben los economistas contribuye a las decisiones que los economistas toman en su condición de ministros. La creencia de que las cuestiones económicas son centrales para la acción de los gobiernos y para las relaciones internacionales ha convertido el despliegue de ministros con $\mathrm{Ph}$. D. en un nuevo instrumento de legitimación política. Esta creencia ha hecho que el lenguaje profesional de los economistas se convierta en una lingua franca política y ha estimulado a que los contactos y los valores profesionales transnacionales se conviertan en un contexto significativo para la adopción de decisiones políticas nacionales... Es necesario además tomar en cuenta la importancia de la incertidumbre que rodea la gestión económica en una época en la que los problemas económicos son vistos como cuestiones centrales a la vida política. La ansiedad de la incertidumbre confiere un gran poder a aquellos que proclaman ser miembros de una profesión que se supone posee el conocimiento capaz de diluir la ansiedad" (MARKOFF Y MONTECINOS, 1994: 6)

8. "El análisis económico no sólo tiene un papel significativo en la búsqueda de soluciones a los problemas técnicos de los estados sino que también lo tiene en la elaboración de sus políticas por medio de un lenguaje que les confiere legitimidad. Esta es una manifestación de la importancia retórica del discurso de los expertos" (MARKOFF Y MONTECINOS, 1994: 11). 
- La liberalización cambiaria y comercial estimulan la competitividad de la industria nacional.

- El mercado conduce a situaciones óptimas.

- Siempre y en todo lugar es mejor menos que más Estado.

La aceptación de estas premisas ha reducido los alcances del debate económico en Colombia. Las universidades no están participando en la discusión. El pensamiento único ha llevado a que problemas fundamentales, como el impacto que tiene el modelo de desarrollo en la agudización de la guerra, no hagan parte de la agenda investigativa.

Las mesas de discusión del proceso de paz deben alimentarse con argumentos académicos que ayuden a develar el manto ideológico que cubre las afirmaciones simplistas del discurso neoliberal.

\section{GLOBALIZACIÓN Y FRAGILIDAD FINANCIERA}

Las crisis financieras de octubre del 87 y de noviembre del 97 reflejan problemas estructurales del ordenamiento económico internacional. A finales de septiembre del 97, y con el propósito de conmemorar los diez años del crash del 87 , la CNN realizó un programa sobre el funcionamiento de las bolsas del mundo. El título era: "Nunca Más". A lo largo del programa entrevistaban a los presidentes de las principales bolsas, quienes iban explicando las regulaciones adoptadas en estos diez años. Para ellos no había duda de que las nuevas medidas evitarían que se repitiera el fenómeno del 87. Todos coincidían en que "nunca más". Pero apenas mes y medio después se desplomaron los mercados asiáticos. Contra todas las previsiones, en noviembre del 97, el sistema financiero internacional volvió a temblar. Las burbujas especulativas estallaron y los precios de las acciones cayeron. La crisis del 87 no fue la última, como tampoco lo será la que comenzó en el 97 . El sistema financiero internacional es frágil ${ }^{9}$. Y recientemente, estos choques han hecho temblar a tres de los cinco vecinos colombianos: Brasil, Venezuela y Ecuador.

La volatilidad del sistema financiero internacional ha tenido un impacto enorme en la economía colombiana, especialmente después de que se realizó la liberación cambiaria a comienzos de los años noventa. El país todavía no se ha recuperado del shock producido por las decisiones que tomó la administración Gaviria (1990-1994) en los frentes cambiario y comercial. Viendo los hechos con una perspectiva de mediano plazo, el efecto más perverso de la forma apresurada como se realizaron las aperturas cambiaria y comercial ha sido la pérdida de competitividad de la industria y del sector agropecuario.

El estudio nacional sobre productividad (Chica, 1996) concluye que la apertura ha tenido un impacto negativo en la productividad de la industria y de la agroindustria. Chica, el coordinador del estudio, llega a esta conclusión después de hacer un balance de los aspectos positivos y negativos de la apertura ${ }^{10}$. Los resultados de la investigación de Garay tampoco son alentadores.
"En Colombia viene presentándose, desde la década de los ochenta, una progresiva desindustrialización a favor de una relativa terciarización de la economía. Este fenómeno, aunque no es exclusivo para Colombia (otros países de la región han disminuido la participación industrial en el PIB), sí comenzó a suceder con anterioridad a los demás países del área y se profundizó en los últimos años de apertura económica" (Garay, 1998: 523).

Por el lado de la agricultura el panorama es más dramático. Entre 1991 y 1997 las importaciones agropecuarias aumentaron $500 \%$, mientras que las exportaciones apenas crecieron $24 \%$. En este período, el área cosechada de los cultivos transitorios (sorgo, maíz, arroz, cebada, trigo, algodón y soya) se redujo en 780.000 hectáreas. La de los cultivos permanentes diferentes al café (banano, flores, palma africana, caña de azúcar y panelera) aumentó 300.000 hectáreas. El balance neto sería una reducción de 480.000 hectáreas ${ }^{11}$

La mención de lo que ha sucedido con la industria y la agricultura muestra que la tasa de sacrificio de la política monetaria no ha sido cero. Que las decisiones que se han tomado en el frente monetario, especialmente en materia cambiaria, han tenido fuertes repercusiones en la actividad real.

Como la mayoría de los países, Colombia también ha experimentado dos fenómenos que se desprenden directamente de la globalización financiera. El primero tiene que ver con la creciente separación de las transacciones monetarias frente a las transacciones reales. El segundo se expresa en una pérdida de autonomía de las políticas fiscal y monetaria.

La falta de coherencia entre las operaciones monetarias y los intercambios reales siempre ha preocupado a los economistas. Las crisis de octubre del 87 y de noviembre del 97 expresan esta disfunción. Los movimientos monetarios van adquiriendo tal autonomía que, finalmente, escapan a cualquier control. Las entidades financieras internacionales son incapaces de regular los movimientos de los flujos de los capitales internacionales. A medida que las operaciones especulativas se extienden, van perdiendo su vínculo con el mundo real. La burbuja financiera estalla cuando el distanciamiento del mundo real se hace insostenible. Los precios de las acciones no pueden subir indefinidamente. Mucho menos, cuando este valoración de los activos bursátiles no

9. Entre otros, Keynes (1936), Hicks (1966), Minsky (1986), Triffin (1989) y Shackle (1972), han mostrado que a medida que las operaciones financieras, monetarias y bursátiles se amplían y se tecnifican, el conjunto del sistema se va debilitando. En días pasados, Tobin (1998) ha llamado nuevamente la atención sobre la necesidad de regular los flujos de los capitales internacionales, con el fin de disminuir sus efectos desestabilizadores.

10. La revaluación del peso, que ha sido uno de los rasgos más distintivos de la economía colombiana durante los noventa, tiene la ventaja de que disminuye el costo de la maquinaria y de los insumos importados. Pero, al mismo tiempo, genera efectos perversos como el incremento del costo de los salarios medidos en dólares. Sobre este último punto, ver Riveros (1995).

11. Sobre este punto véase, también, Aldana (1997) 
corresponde con una reactivación de la producción y la competitividad de la industria ${ }^{12}$.

Keynes decía que la elección lleva consigo intercambios monetarios. De los tres motivos keynesianos para demandar dinero: transacciones, precaución y especulativo, los dos últimos dependen del nivel de incertidumbre. La desconfianza frente al futuro impide que todo el dinero se destine a las transacciones ${ }^{13}$. Los individuos guardan una parte del dinero e interrumpen el ciclo de compra y venta. La demanda "voluntaria" de dinero, como la llama Keynes, crea un desbalance que obliga a realizar transacciones por fuera del equilibrio. La secuencia mercancía - moneda $\Rightarrow$ moneda- mercancía se rompe al introducir la especulación (Hahn, 1970: 3), que es una de las manifestaciones de la demanda "voluntaria" de dinero. El cambio de mercancía a moneda no tiene mayor dificultad. La situación se complica al tratar de realizar el segundo paso, ya que quien posee moneda no necesariamente está dispuesto a adquirir mercancías ${ }^{14}$.

La ruptura entre las transacciones monetarias y reales se ha agudizado con la globalización financiera. En Colombia, durante los noventa, las tendencias especulativas han tenido un notable desarrollado. Hay tres hechos que apoyan este diagnóstico: el déficit de balanza comercial, la revaluación de la tasa de cambio y el aumento de las tasa de interés doméstica.

A diferencia de otras economías del mundo, el deterioro de la balanza en la cuenta corriente que se observa desde el 91 ha estado acompañado de un aumento de las reservas y de una revaluación del peso. El superávit de la cuenta de capitales ha compensado con creces el déficit corriente, lo que se ha traducido en un crecimiento continuo de las reservas. Esta tendencia apenas comenzó a modificarse en el año 98. Para evitar el impacto inflacionario del exceso de divisas, la autoridad monetaria permitió que la tasa de interés interna subiera, colocándola por encima de los patrones internacionales.

El círculo especulativo es: 1) entrada de capitales internacionales, 2) revaluación del peso, 3) aumento de la tasa de interés interna y, nuevamente, 1) más entrada de capitales internacionales... y el ciclo recomienza. Esta dinámica especulativa golpeó duramente a la industria y a la agricultura. La caída del empleo es el último eslabón del proceso. Los dineros del narcotráfico han alimentado la corriente especulativa.

La situación se complica porque en medio de las tendencias especulativas, la lucha contra la inflación se ha convertido en el objetivo central de la política económica. Los esfuerzos por lograr la meta inflacionaria han obligado a realizar grandes sacrificios, que se han traducido en una disminución de la producción y el empleo.

La inflación colombiana gira alrededor del $20 \%$. Es el ejemplo internacional de "inflación moderada". Krugman (1995) dice que frente a situaciones hiperinflacionarias, como las que vivieron muchos países de América Latina, la lucha contra la inflación obliga a realizar grandes sacrificios. Inflaciones del 100\% o, incluso, del $1000 \%$ son inaceptables. Pero, agrega, cuando la inflación bordea el $20 \%$, no se justifica sacrificar la actividad real ${ }^{15}$. Las autoridades económicas colombianas tienen otra visión. Están decididas a continuar dándoles prioridad a los objetivos monetarios. No importa cuál sea el costo. En el seminario del BID en Cartagena (marzo 16 del 98), el ministro de Hacienda de Colombia dijo que, de ser necesario, continuaría aumentando la tasa de interés con el fin de defender la banda cambiaria. Insistió en que para él no había duda de que la estabilidad cambiaria y monetaria era prioritaria, aún si ello implicaba reducir la tasa de crecimiento de la economía. Un año después, el nuevo gobierno reconocía que las tasas de interés habían llegado a niveles insostenibles y que, para enfrentar la recesión, era indispensable reducir las tasas de interés.

\section{DEBILIDAD DEL TRÍPODE SOBRE EL QUE SE CONSTRUYE LA ESTABILIDAD MACROECO- NÓMICA.}

La estabilidad macroeconómica se ha fundado en un trípode con patas desiguales. Primero, la globalización financiera y comercial que impone reglas y condiciones exógenas. Segundo, la política monetaria que es sumamente volátil. Sus movimientos pueden registrarse segundo a segundo en las

12. El distanciamiento entre las operaciones reales y las monetarias ha preocupado a autores de muy diversas escuelas. Por el lado marxista se destaca el estudio de Brunhoff (1973). La autora examina la crisis inflacionaria de los años setenta y muestra que la decisión de Nixon de renunciar a la convertibilidad del dólar en oro, generó un ambiente propicio a la especulación. Desde ese momento, 15 de agosto de 1971, se abren las puertas a una dinámica especulativa incontrolable. Las políticas monetarias nacionales "...son perturbadas por movimientos especulativos incontrolables que afectan el papel del dólar como moneda internacional. La inundación de dólares, debida a la persistencia del déficit de la balanza de pagos y al abandono de las autoridades monetarias norteamericanas desde principios de 1971, suscitó la desconfianza en cuanto al valor futuro de esta moneda. Los "especuladores internacionales" se desembarazaron de ella, a cambio de monedas reputadas como fuertes y susceptibles de ser revaluadas" (BRUNHOFF, 1973: 13). MINSKY (1986) y TRIFFIN (1989) también han analizado las características de los procesos especulativos en el mercado internacional de capitales. Triffin, especialmente, ha sido muy crítico del ordenamiento del sistema financiero. Desde una perspectiva más ortodoxa, CLOWER (1967) ha insistido que en una economía monetaria las transacciones no son de bienes con bienes, sino de bienes con mone$\mathrm{da}$. Distingue entre las demandas nocional y efectiva. La demanda nocional, que sería compatible con el equilibrio, no coincide con la demanda que efectivamente se presenta en el mundo real. La falta de correspondencia entre ambos tipos de demanda ha obligado a pensar en los problemas relacionados con las expectativas, el desequilibrio y las limitaciones que tienen los precios como mecanismos eficientes de asignación. "La insistencia de Clower en el papel único que cumple la moneda reforzó el estudio de las diferencias entre las economías de intercambio y monetaria y ayudó a combatir la visión de que en la macroeconomía la moneda no importaba, porque los numerarios no importan en los sistemas neowalrasianos" (WEINTRAUB, 1979: 78).

13. Refiriéndose a la tasa de interés y a la incertidumbre frente al futuro, dice Shackle: "No es la impaciencia, sino la ignorancia, lo que entra en escena a través de la brecha temporal entre el préstamo y el pago" (SHACKLE, 1972: 203, subrayado mío).

14. "...si alguna vez se escribe seriamente una teoría monetaria, debe tenerse en cuenta que es de considerable importancia el hecho de que los contratos se realicen en términos monetarios" (ARROW y HAHN, 1971:357).

15. “...los costos de la inflación-definida como la reducción global en el ingreso real-son tan bajos que causan molestia [a quienes se empeñan en la lucha anti-inflacionaria]. No hay duda de que inflaciones muy altas, de tres o cuatro dígitos, que desgraciadamente han sido comunes en la historia de América Latina, causan problemas en el funcionamiento de la economía de mercado. Pero es muy difícil obtener ganancias de una reducción de la tasa de inflación, por decir algo, del 20\% al 2\%. Más aún, los métodos usados para conseguir la deflación en los países en desarrollo, especialmente el uso de una tasa de cambio fija con el fin de ganar credibilidad, han tenido costos muy serios" (KRUGMAN, 1995 33). 
bolsas de valores. Y, tercero, la política fiscal que es rígida e inflexible. La Comisión de Racionalización del Gasto (1997) llama la atención sobre la poca discrecionalidad del manejo fiscal. Es tal la rigidez del presupuesto que la Comisión de Racionalización considera que es un instrumento de política económica "inocuo".

La secuencia comienza con los flujos de los capitales internacionales, después continúa con la política monetaria que, finalmente, termina incidiendo en el presupuesto. Por consiguiente, el origen del problema está en los flujos de capitales y no en la política fiscal. Comparto la idea de Tobin (1998) de frenar los movimientos internacionales de capitales mediante impuestos. Ello disminuye la volatilidad y los choques desestabilizadores.

Las dinámicas de los movimientos de capitales y del presupuesto son radicalmente diferentes. Mientras que los movimientos de capitales son ágiles e inciertos, el presupuesto es inflexible y, hasta cierto punto, más predecible. Especialmente durante los noventa, la política monetaria ha estado respondiendo a los embates de los capitales internacionales. Por su naturaleza, la política monetaria puede reaccionar rápidamente a los choques externos. Estos movimientos bruscos son desestabilizadores. Como señalaba atrás, el impacto estructural de largo plazo termina sintiéndose en la producción y ello afecta los niveles de tributación. Cuando la actividad económica es floreciente, los impuestos también crecen. Hay una relación muy estrecha entre el ciclo económico y los tributos. En cambio, el gasto público, es mucho más inercial.

Actualmente, los ingresos corrientes solamente alcanzan para financiar el $57 \%$ de los gastos corrientes (Comisión, 1997). Los gastos que están creciendo más rápidamente son: las transferencias para la seguridad social, la defensa y la justicia, el servicio de la deuda, las transferencias para los municipios y departamentos. Además, continúan las dificultades financieras del sector eléctrico.

Con razón, la Comisión de Racionalización destaca los impactos intertemporales del déficit, especialmente cuando se refiere a la seguridad social y a la deuda pública. El valor presente del pasivo pensional equivale al $80.4 \%$ del PIB (Comisión, 1997 b:79).

En cuanto a la defensa y la justicia, es claro que vamos hacia un Estado cada vez más gendarme. Esta característica del Estado se observa a través de la dinámica del empleo público. Entre 1985 y 1995 la participación del pie de fuerza de las policía y del ejército en el empleo público del orden nacional (niveles central y descentralizado) aumentó del $32.5 \%$ al $41 \%{ }^{16}$. Entre tanto, la de los maestros se redujo del $46.1 \%$ al 41\% (Comisión de Racionalización, 1997 c: 142143). Este crecimiento del pie de fuerza atiza la violencia.

Desde la perspectiva institucional, la Comisión insiste en la necesidad de mejorar la gerencia pública y la eficiencia en el manejo del gasto. Quizá porque no era su propósito, la Comisión de Racionalización se quedó corta en el examen de las implicaciones que se derivan de la pérdida de discrecionalidad de la política fiscal. Puesto que el grado de intervención no puede ser regulado, el margen de maniobra de la política fiscal es mínimo. Esta constatación golpea tanto a los keynesianos que han defendido las bondades de la acción contracíclica del Estado, como a los monetaristas que consideran que la intervención debe circunscribirse a la estabilidad monetaria.

Estos enfoques basados en la discrecionalidad de las políticas fiscal y monetaria, dejan de ser pertinentes cuando el presupuesto es inflexible e "inocuo como instrumento de gestión y evaluación”. La política fiscal no puede responder ágilmente a los choques causados por los movimientos de capitales (Heller, 1997). Deja de cumplir la función contracíclica keynesiana. La temporalidad de los movimientos de capital es demasiado corta frente a la lentitud de las transformaciones fiscales. La primacía de la política monetaria sobre la fiscal limita las posibilidades de realizar programaciones de largo plazo, ya que los movimientos de los capitales internacionales, que finalmente son los que determinan la política monetaria, son erráticos e impredecibles.

\section{ECONOMÍA VIOLENCIA Y PAZ}

De acuerdo con las estimaciones de la Misión Social del DNP ${ }^{17}$, en Colombia el número de pobres por Línea de Pobreza (LP) pasó de 14.8 millones en 1978 a 18.9 millones en 1995. La cifra absoluta crece a pesar de que el porcentaje de pobres disminuyó de $58.1 \%$ a $53.8 \%$. La medición de la pobreza por LP considera explícitamente el ingreso corriente y por ello es muy sensible al ciclo económico ${ }^{18}$. En el mismo período, el Gini aumentó de 0.542 a 0.556 . La mayor pobreza absoluta, medida por LP, ha ido a la par con un deterioro en la distribución del ingreso laboral ${ }^{19}$.

La situación social del país se ha deteriorado y, de alguna manera, la política económica y el modelo de desarrollo tienen una parte de responsabilidad en la agudización de la violencia. La desigual distribución de la riqueza ha sido caldo de cultivo de la violencia (DNP 1998). Pero, a su vez, un modelo económico que ha favorecido la especulación y que ha sacrificado el desarrollo productivo para poder ser fiel a la ortodoxia monetaria, ha terminado estimulando la concentración y propiciando la exclusión. Sen (1973: 1) dice que la desigualdad y la rebelión van de la mano. Y aunque la desigualdad puede ser un poderoso ingrediente de la rebelión, no hay una relación mecánica entre ambas. A pesar de su mutua relación, de lo uno no se deriva necesariamente lo otro. Las interacciones son complejas y están mediadas por factores culturales, antropológicos y sociales. En esta malla

16. Si a este porcentaje se le suma las personas que trabajan en actividades administrativas $(3.7 \%)$ y, además, se añaden los funcionarios vinculados a los organismos de justicia $(6.9 \%)$ y al DAS $(1.1 \%)$, la participación aumenta de $41 \%$ a $52.7 \%$.

17. Véase Nina (1997).

18. Hay otras medidas, como el indicador de Necesidades Básicas Insatisfechas (NBI), que está más relacionado con la vivienda y la infraestructura de servicios básicos. A diferencia de la LP, el NBI refleja cambios de más largo plazo. Medido por NBI, el número absoluto de pobres ha disminuido. Este avance se explica por: la urbanización, la ampliación de la cobertura de los servicios públicos y el mayor nivel educativo. En los últimos años ha aumentado el gasto público social y ello ha incidido positivamente en la reducción del NBI.

19. Nos referimos al ingreso laboral porque las estimaciones están basadas en las Encuestas de Hogares del Departamento Administrativo Nacional de Estadística (DANE). 
de interrelaciones, la percepción que tengan las personas de su situación es fundamental. Los individuos, continúa Sen, sólo expresan su inconformidad frente a la desigualdad cuando de alguna manera sienten que la rebelión puede tener algún efecto. Mientras tanto, los desfavorecidos aceptan con resignación la desigualdad y terminan incorporándola a su cosmovisión de tal forma que sea llevadera.

Los organismos internacionales le han dado mucho énfasis a la lucha contra la pobreza, dejando de lado el combate a la desigualdad. El énfasis debería cambiar, de tal manera que la preocupación por una mejor distribución del ingreso pase a ser el centro de la discusión. El último informe del BID (1998) avanza positivamente en esta dirección. Muestra que América Latina es la región más desigual del mundo.

Es urgente repensar nuestro modelo de desarrollo, con el fin de estimular políticas que favoreciendo la equidad, también contribuyan a reducir la pobreza. No hay una relación mecánica entre equidad, desarrollo y menor pobreza. Sin embargo, la mejor equidad es compatible con un mayor desarrollo y con una disminución de la pobreza.

Sobre la relación entre equidad y desarrollo, el debate ha girado alrededor de la curva de Kuznets (1955). La U invertida de Kuznets es, ante todo, una constatación. Y, por tanto, no es pertinente interpretarla de la manera usual, como una causalidad que va del crecimiento hacia la distribución. La otra secuencia, que va de la distribución hacia el crecimiento, también es compatible con la constatación de Kuznets. Estudios recientes, como los de Piketty (1994) y Jaramillo (1995), muestran que no hay que esperar a crecer para distribuir. Por el contrario, la distribución favorece el crecimiento.

La pobreza y la equidad no van siempre en la misma dirección. Hay países con un elevado ingreso promedio y con poca pobreza, pero muy desiguales. Kuwait podría ser un buen ejemplo. Hay otros países que siendo pobres son equitativos. Reconociendo la complejidad de estas interacciones, debe dársele prioridad a las políticas que contribuyen a reducir la concentración de la riqueza. Puesto que la mayor equidad es compatible con un crecimiento más dinámico, la disminución de la desigualdad terminará aliviando las condiciones de los pobres.

Así que debe buscarse un enfoque estructural que integre lo económico y lo social. Pero el énfasis de la lucha contra la pobreza debe desplazarse hacia la lucha contra la desigualdad. Este cambio de óptica tiene tres ventajas:

- Es integral. La lucha contra la desigualdad puede hacer parte integral de las medidas estructurales mucho más fácilmente que la lucha contra la pobreza ${ }^{20}$.

- Subsume la lucha contra la pobreza. En Colombia el combate a la pobreza puede ser más eficiente si está mediado por políticas tendientes a reducir la desigualdad.

- Contribuye a la paz. Dado que la desigualdad incuba la violencia, la equidad abre espacios favorables a la paz.

De las mesas de negociación no deben resultar un número interminable de compromisos. Es preferible llegar a acuerdos sobre pocos aspectos esenciales. Y la lucha contra la desigualdad debería ser uno de ellos. Si se toma en serio, este propósito llevaría a repensar un modelo de desarrollo que ha estado fundado en una apertura indiscriminada y en una absolutización de la lógica del mercado.

\section{REFERENCIAS BIBLIOGRÁFICAS}

Aldana, Camilo (1997): “Catástrofe y Transformación”, Portafolio, El Tiempo, 21 de nov., p. 7.

ARROW, Kenneth (1995): "Interview to Kenneth Arrow", Region, Federal Reserve Bank of Minneapolis, http://woodrow.mpls. frb.fed.us.

ARROW, Kenneth y HAHN, Frank (1971): General Competitive Analysis, San Francisco: Holden-Day.

BANCO INTERAMERICANO DE DESARROLLO, BID (1998): América Latina Frente a la Desigualdad. Progreso Económico y Social en América Latina. Informe 1998-1999. Washington.

BRunhoff, Suzanne (1973): La Política Monetaria. México, 1978.

CHICA, Ricardo (1996): El Crecimiento de la Productividad en Colombia, DNP, Colciencias, Fonade.

ClOWER, Robert (1967): "A Reconsideration of the Microfundamentations of Monetary Theory”, Western Economic Journal, dec., 6 (1), 202-212.

COMISIÓN DE RACIONALIZACIÓN DEL GASTO Y DE LAS FinANZAS PÚBLICAS (1997). El Saneamiento Fiscal, un Compromiso de la Sociedad. Tema I Diagnóstico y Principales Recomendaciones. Ministerio de Hacienda y Crédito Público.

Comisión de Racionalización del Gasto y de las Finanzas Públicas (1997 b): "Deuda Pública Consolidada", en El Saneamiento Fiscal, un Compromiso de la Sociedad. Tema IV. Sistema de Pensiones. Deuda Pública, 77-119. Ministerio de Hacienda y Crédito Público,

COMIsión de Racionalización del GaSto y de las FinanZas Públicas (1997 c): "Empleo y Salarios del Sector Público Colombiano", en El Saneamiento Fiscal, un Compromiso de la Sociedad. Tema II. Admi nistración del Estado, 117-176. Ministerio de Hacienda y Crédito Público.

Departamento Nacional de Planeación, DNP (1998): La Paz: El Desafío para el Desarrollo. Tercer Mundo, DNP.

FRIEDMAN, Milton (1993): Entrevista transcrita en SNOWdON, Brian.; VANE, Howard., WynARCZYK, Peter (1994): A Modern Guide to Macroeconomics. An Introduction to Competing Schools of Thought, 171-178 Edward Elgar, University Press, Cambridge.

GARAY, Luis (1998) direc.: Colombia: Estructura Industrial e Internacio nalización 1967-1996. Bogotá: DNP.

GONZÁLEZ, Jorge (1999): "La Fetichización del Currículo y la Absolutización del Libro de Texto", en BEjarano, Jesús (comp): Hacia Dónde Va la Ciencia Económica en Colombia. Siete Ensayos Exploratorios, 53-88, Tercer Mundo, Colciencias, Universidad Externado de Colombia

HaHN, Frank (1970): "Some Adjustment Problems", Econometrica, jan. 38 (1), 1-17.

Heller, Peter (1997): Fiscal Policy Management in an Open Capital Regime, IMF Working Paper, WP/97/20.

HiCKs, John (1966): "Las Dos Tríadas", en Ensayos Críticos sobre Teoría Monetaria, 15-81. Barcelona, Ed. Ariel, 1975.

JARAMILLO, Fernando (1995): "El Efecto de la Igualdad sobre el Crecimiento Económico”, en Desarrollo y Sociedad, no. 35, marzo, 115-141.

KEYNES, John Maynard (1936): Teoria General de la Ocupación, el Interés y el Dinero. México: Fondo de Cultura Económica, 1976

Krugman, Paul (1995): "Dutch Tulip and Emerging Markets", en Foreign Affairs, vol. 74, july-august, 28-44.

KUZNETS, Simon (1955): "Economics Growth and Income Inequality", en American Economic Review, 45, (1), march, 1-28.

LUCAS, Robert (1976): "Econometric Policy Evaluation: A Critique", en BRUNNER, Karl., ed. The Phillips Curve and Labor Markets (supplement to the Journal of Monetary Economics), 19-46.

LuCAS, Robert (1987): Models of Business Cycles. Inglaterra: Basil Blackwell.

20. En este campo la tradición económica es muy rica. Los criterios de compensación de Kaldor, Hicks y Scitovsky, por ejemplo, dan pie para pensar en un esquema de desarrollo que integre la lucha contra la desigualdad. 
MARKOFF, John y MONTECINOS, Verónica (1994): "El Irresistible Ascenso de los Economistas", en Desarrollo Económico, vol. 34, no. 133, abriljunio, 3-29.

MINSKY, Hyman (1986): Stabilizing an Unstable Economy, Yale University Press.

NinA, Esteban (1997): Análisis de la Evolución del Perfil de Pobreza y la Desigualdad en Colombia: 1978, 1988, 1991-1995, DNP, Misión Social, policopiado.

PIKETTY, Thomas (1994): "Inégalités et Redistribution. Développements Théoriques Récents”, en Revue Economie Politique, 104 (6), nov.-déc., 770-800.

Rawls, John (1971): Teoría de la Justicia. México: Fondo de Cultura Económica, 1985.

RaWLS, John (1980): “Kantian Constructivism in Moral Theory”, en Journal of Philosophy, 77, 515-572.

RIVEROS, Luis (1995): Minium Wages in Latin America: The Controversy About Their Likely Economic Effects, Universidad de Chile, policopiado.
SARgEnT, Thomas (1987): Dynamic Macroeconomic Theory, Harvard University Press.

SEN, Amartya (1973): On Economic Inequality, Oxford University Press. SEN, Amartya (1987): On Ethics and Economics, Basil Blackwell, Oxford. SHACKLE, George Lennox Sharman (1972): Epistemics and Economics, Cambridge: Cambridge University Press, reprint Transaction Publishers, New Brunswick, New Jersey, 1992.

SMITH, Adam (1776): La Riqueza de las Naciones. Madrid: Alianza Editorial, 1994.

ToBIN, James (1998): “Entrevista a James Tobin”, Le Monde, 17 noviembre. TRIFFIN, Robert (1989): Le Déséquilibre Monétaire Mondial, Université Catholique de Louvain, policopiado.

WaLRAS, Léon (1887): Elements of Pure Economics, London, Allen and Unwin, 1954.

Weintraub, Roy (1979): Microfoundations. The Compatibility of Microeconomics and Macroeconomis, Cambridge University Press.

\section{RESUMEN}

El eje del artículo es la relación que establece el autor entre desarrollo económico y violencia. En Colombia la situación económica se ha deteriorado en gran medida como consecuencia de la política económica y del modelo de desarrollo y éstos son responsables de la agudización de la violencia. La desigual distribución de la riqueza y la ortodoxia monetaria han estimulado la concentración y han propiciado la exclusión. Aunque la relación no es mecánica, esta situación es un elemento para la rebelión.

El costo social de la política económica neoliberal ha sido elevado, a pesar de que los programas sociales han puesto énfasis en la lucha contra la pobreza. Este enfoque debe modificarse, puesto que privilegiando la equidad y aminorando la concentración del ingreso, se estimula el desarrollo, se reduce la pobreza y en consecuencia, se crea un clima propicio para el diálogo y la paz.

Palabras clave: desarrollo económico, distribución de la riqueza, política económica neoliberal, violencia, pobreza, exclusión.

\section{ABSTRACT}

The core of the article is the relationship between economic development and violence that the author establishes. The economic situation in Colombia has been deterioring as consequence of the economic policy and the way of development. Both of them are responsibles of the violence intensification.

The unequal wealth distribution and monetary orthodoxy have stimulated the concentration and have created a favorable atmosphere for exclusion.

The social cost of neoliberal economic policies has been high despite the fact that social programs have focused on fighting poverty. This approach must be modified. Development is stimulated by granting privilege to equality and reducing the income concentration. In doing so, the rigth atmosphere for dialogue and peace is created.

Key words: economic development, wealth distribution, neoliberal economic policies, violence, poverty, exclusion. 


\section{RED DE UNIVERSIDADES POR LA PAZ Y LA CONVIVENCIA PRIMER CONGRESO UNIVERSITARIO POR LA PAZ}

\section{DECLARACION FINAL}

Los participantes en el Primer Congreso Universitario por la Paz, convencidos de la responsabilidad que tiene la Universidad y sus distintos estamentos con el país, en un momento en que la guerra interna crea incertidumbres y temores sobre toda la sociedad, pero en el cual hay esfuerzos por buscar una superación negociada de la misma, declaramos que:

1. Apoyamos totalmente el proceso de negociaciones que se viene desarrollando entre el Gobierno Nacional y las FARC y esperamos que en sus actuaciones tengan en cuentan su responsabilidad histórica para con la $\mathrm{Na}$ ción toda.

2. Solicitamos al Gobierno Nacional y al ELN que hagan todos los esfuerzos para superar las dificultades que hoy día entraban el proceso de Convención Nacional, sumándonos de esta manera a la demanda que en este sentido esta haciendo toda la sociedad colombiana.

3. La superación de la guerra interna que nos esta matando a los colombianos requiere no solamente una cesación del fuego sino comenzar un proceso de construcción de la paz con justicia social que permita resolver las profundas inequidades que están presentes en la sociedad y contener los regresivos efectos sociales generados por el actual modelo de desarrollo neoliberal.

4. Condenamos todas las atrocidades de la guerra y en especial los secuestros, desapariciones forzadas, masacres, asesinatos selectivos, desplazamientos y demás hechos de violencia que afectan a la población civil no combatiente.

5. Rechazamos de manera enfática los asesinatos de miembros de la comunidad académica, en especial el del profesor de la Universidad de Antioquia Hernán Henao y solicitamos a los actores del conflicto armado que la Universidad no sea convertida en un campo de batalla de sus guerras. La Universidad esta siempre abierta al debate de las propuestas e ideas de distinto signo, con la única condición que sea la fuerza de la razón que prime, y no la razón de la fuerza.

6. Expresamos nuestra profunda preocupación por la desaparición del profesor de la Universidad Pedagógica Nacional Dario Betancourt y exigimos a sus captores que nos lo sea devuelto a la mayor brevedad para seguir recibiendo sus enseñanzas y para que su familia disfrute de sus afectos.

7. La Universidad se compromete a ofrecer sus aportes y contribuciones para el análisis y búsqueda de solución de los problemas nacionales asociados al conflicto armando, entendiendo que esa es parte de su responsabilidad para con la sociedad y su futuro.

8. Consideramos que la superación negociada del conflicto armado colombiano no puede ser hecha de espaldas al país, debe ser un proceso democrático y participativo que convoque a toda la sociedad y la academia debe ser tenida en cuenta como un actor polifónico que tiene mucho que decir y mucho que aportar.

9. La red de Universidades se compromete a impulsar y promover el desarrollo de cátedras de cultura de paz que fomenten las iniciativas de compromiso de transformación social de los ciudadanos y ciudadanas como gestores de paz, además de potenciar la consolidación de pedagogías de la paz y prevención de la violencia en la vida cotidiana y en el ámbito de las instituciones educativas y sociales. En este sentido, se considera fundamental el papel de los medios de comunicación para coadyuvar a la construcción de la paz con justicia social.

Santafé de Bogotá, mayo 14 de 1999 